\title{
Artikel
}

\section{Nieuwe inzichten in de motorische problemen bij DCD en mogelijkheden voor training}

\author{
Imke L. J. Adams · Jessica M. Lust · Bert Steenbergen
}

\section{Samenvatting}

Kinderen met Developmental Coordination Disorder (DCD) ervaren motorische problemen tijdens het uitvoeren van vele activiteiten. Deze kinderen hebben problemen met de coördinatie van zowel de fijne motoriek (bijv. schrijven, veters strikken) als de grove motoriek (bijv. een bal gooien, hinkelen). Deze motorische problemen hebben invloed op het dagelijks functioneren van deze kinderen en op hun schoolprestaties. Uit recente studies komt naar voren dat problemen met het voorspellen van de uitkomst van een geïnitieerde beweging een mogelijk belangrijke bijdrage levert aan de motorische problemen bij DCD. Deze studies hebben zowel motorische inbeelding als motorische planning onder de loep genomen. In dit artikel bespreken we drie vragen: 1) Welk bewijs is er dat kinderen met DCD moeite hebben met het voorspellen van de uitkomst van een beweging? 2) Hoe verandert deze vaardigheid om motorisch in te beelden en te plannen in de loop van de tijd bij kinderen met $D C D$ ? 3 ) Is het motorische inbeeldingsvermogen te trainen bij kinderen met DCD en heeft dat effect op het motorisch functioneren?

Trefwoorden developmental coordination disorder (DCD) - motoriek · motorische inbeelding · bewegingsplanning

Dit artikel is gebaseerd op het proefschrift van Imke Adams die zal worden verdedigd op 11 januari 2018 aan de Radboud Universiteit in Nijmegen.

I. L. J.Adams ( $\triangle)$. J. M. Lust ·B. Steenbergen

Behavioural Science Institute, Radboud Universiteit,

Nijmegen, Nederland

e-mail: i.adams@pwo.ru.nl

B. Steenbergen

School of Psychology, Centre for Disability and Development

Research, Australian Catholic University, Melbourne, Australia

\section{Inleiding}

Kinderen met verminderde motorische vaardigheden hebben moeite om tijdens de gym of een sportles mee te komen met hun leeftijdgenoten. Dit kan zich uiten als enkel wat onhandigheid, maar bij kinderen met developmental coordination disorder (DCD) is deze onhandigheid prominenter aanwezig. Op motorische taken, zoals handvaardigheid, balvaardigheid of evenwicht, blijven kinderen met DCD achter bij hun leeftijdgenoten. Dit leidt tot problemen in het dagelijks leven. Zo ervaren deze kinderen problemen bij het aan- en uitkleden of hebben zij problemen op school, bijvoorbeeld bij het leren schrijven. DCD is een formele diagnose, met als criteria: de motorische problemen moeten al vroeg in de ontwikkeling zijn ontstaan, er mag geen sprake 


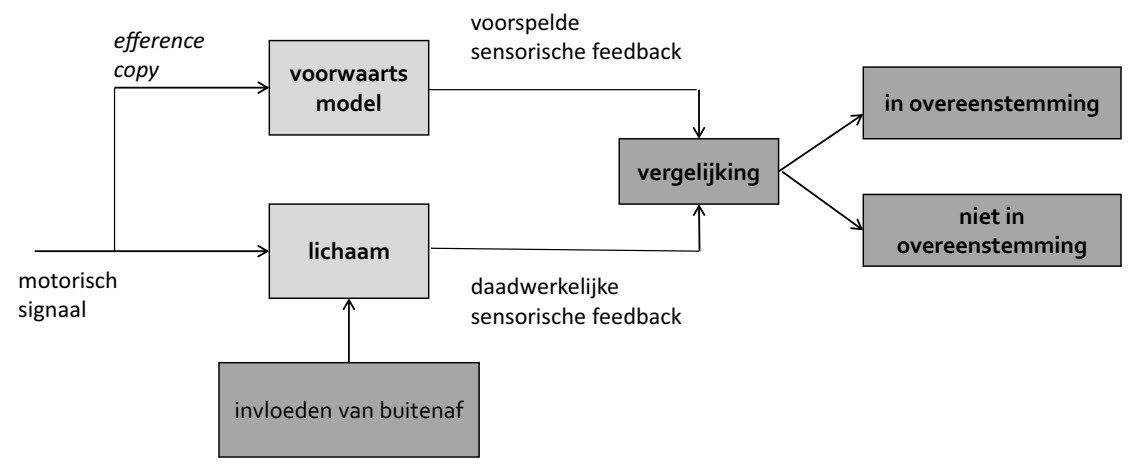

Figuur 1 Intern model voor bewegingscontrole, in overeenstemming met [3].

zijn van een neurologische of visuele aandoening die de motorische problemen kan verklaren en het IQ van het kind moet boven de 70 zijn [1].

De oorzaak van de motorische problemen die kinderen met DCD ervaren, is tot nu toe grotendeels onbekend. Recente studies wijzen erop dat er sprake is van een internal modeling deficit [2], waardoor het plannen van een beweging niet goed verloopt. Op het moment dat iemand een beweging wil maken, wordt een motorisch signaal, of een motorisch commando, geïnitieerd (fig. 1). Dit signaal wordt naar het lichaam, en uiteindelijk naar de spieren gestuurd, teneinde de beweging uit te kunnen voeren. Tegelijkertijd wordt een kopie van dit signaal, de efference copy, naar de pariëtale cortex gestuurd. Met deze efference copy wordt er een voorspelling gemaakt van de sensorische feedback die te verwachten is met het gegeven motorische signaal. De voorspelde sensorische feedback zorgt ervoor dat we bewegingen snel kunnen aanpassen, terwijl we nog aan het bewegen zijn. Dit is een belangrijk aspect van motorische controle. Bovendien heeft deze organisatie als grote voordeel dat er snel kan worden geanticipeerd op de te verwachten sensorische feedback, in tegenstelling tot de daadwerkelijke sensorische feedback, die pas tijdens de uitvoering van de beweging beschikbaar komt. Deze laatste feedback is afkomstig van bijvoorbeeld spieren en gewrichten. Als zowel de voorspelde

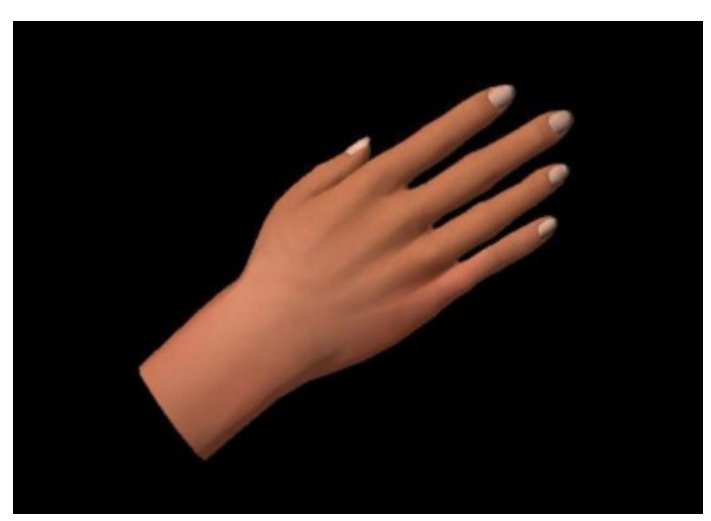

Figuur 2 Voorbeeld van een stimulus in de handrotatietaak (60 graden gedraaid). als de daadwerkelijke sensorische feedback beschikbaar is, kan er een vergelijking tussen worden gemaakt. Op deze manier kan het motorische systeem bewegingen verfijnen en het 'gedrag' van het lichaam leren voorspellen. Problemen met het voorspellen van de uitkomst van een geïnitieerde beweging is mogelijk een van de verklaringen voor de motorische problemen bij kinderen met DCD. De manier waarop een voorspelling van een beweging wordt gemaakt en vervolgens wordt bijgestuurd op basis van een intern model, is schematisch weergegeven in fig. 1 .

\section{Experimenteel bewijs voor een probleem met bewegingsplanning bij kinderen met DCD}

Eerdere studies hebben reeds met behulp van verschillende experimentele taken de bewegingsplanning bij kinderen met DCD onderzocht. Twee paradigma's die daar veel bij zijn gebruikt, zijn motorische inbeelding en motorische planning [4]. Beide zijn gebaseerd op de veronderstelling dat interne modellen van bewegen noodzakelijk zijn om goed te presteren op de taak. De kwaliteit van het intern model wordt op verschillende manieren afgeleid uit de taakprestatie.

Tijdens motorische inbeelding stelt iemand zich een beweging voor (bijvoorbeeld dat hij een voetbal in het doel schiet), zonder dat hij deze beweging daadwerkelijk uitvoert. Er zijn positieve effecten gevonden van motorische inbeelding op de uitvoering van een beweging [5]. Motorische inbeelding is bijvoorbeeld effectief gebleken in de topsport ter verbetering van prestaties [6], maar ook bij de revalidatie van patiënten die een beroerte hebben doorgemaakt blijkt motorische inbeelding effectief te zijn [7, 8]. Dit heeft geleid tot de hypothese dat motorische inbeelding tot een betere prestatie kan leiden, doordat tijdens inbeelding de motorische netwerken worden geactiveerd die ook actief zijn tijdens daadwerkelijk bewegen. Neuro-imaging-onderzoek heeft laten zien dat tijdens motorische inbeelding hersenactiviteit te zien is die sterk lijkt op de hersenactiviteit wanneer de beweging daadwerkelijk wordt uitgevoerd [9]. 


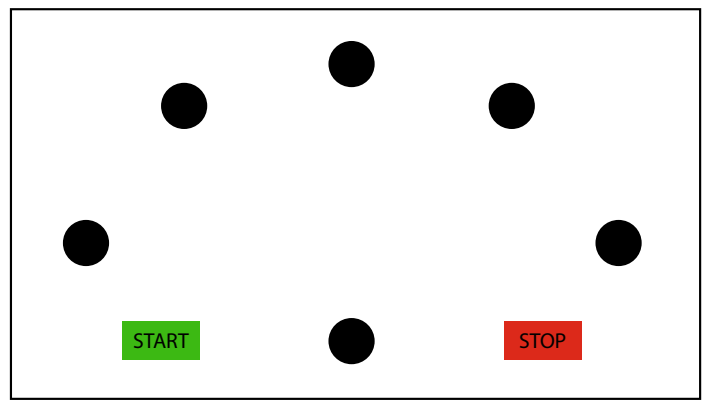

Figuur 3 Schematische weergave van de visual guided pointing task (VGPT).

Het voordeel van motorische inbeelding bij topsporters is dat motorische netwerken worden versterkt zonder dat deze sporters hun spieren verder hoeven te belasten. Bij patiënten die een beroerte hebben doorgemaakt kan revalidatie met behulp van motorische inbeelding soms al starten voordat daadwerkelijk bewegen mogelijk is. Bij onderzoek naar iemands vaardigheid om zich bewegingen in te beelden, worden verschillende experimentele taken gebruikt. Een veel gebruikte motorische inbeeldingstaak is de handrotatietaak (e.g. [10]). Hierbij krijgen proefpersonen een plaatje van een hand te zien die linksom of rechtsom tot wel 180 graden gedraaid kan zijn (fig. 2). Aan de proefpersoon de taak om zo snel mogelijk aan te geven of het daarbij om een linker- of een rechterhand gaat. Er zijn twee manieren waarop deze taak kan worden opgelost: (1) visuele inbeelding waarbij alleen het plaatje in gedachten wordt gedraaid en (2) motorische inbeelding waarbij in gedachten de eigen hand in de richting van het plaatje wordt gedraaid. Wanneer anatomisch moeilijke rotaties leiden tot langere reactietijden wordt aangenomen dat er sprake is geweest van motorische inbeelding. Een ander voorbeeld van een motorische inbeeldingstaak is een doelgerichte wijstaak (visually guided pointing task, VGPT), ook wel de Fitts-taak genoemd (bijv. [11]). Tijdens deze taak moeten proefpersonen wijsbewegingen maken naar een of meer doelen (fig. 3). De duur van deze bewegingen wordt vergeleken met de duur van de bewegingen wanneer deze mentaal moeten worden ingebeeld. Het gebruik van motorische inbeelding wordt afgeleid uit de mate van overeenkomst tussen ingebeelde en uitgevoerde bewegingstijd.

Deze experimentele taken hebben tot doel iemands motorische inbeeldingsvaardigheid in kaart te brengen. Hoe de motorische inbeeldingsvaardigheid getraind kan worden, bespreken we verderop in dit artikel.

Een andere manier om bewegingsplanning te onderzoeken bij kinderen met DCD is gebruik te maken van een motorische planningstaak. Bij motorische planningstaken wordt er gemeten of er bij de inzet van een beweging al rekening gehouden is met het beoogde eindpunt van die beweging. Een goed voorbeeld hiervan is het inschenken van drinken in een kopje dat op z'n kop staat. Over het algemeen zal iemand dit kopje met zijn pink naar boven oppakken, omdraaien, en dan zo eindigen dat zijn pink naar beneden wijst. Het vasthouden van het kopje tijdens het inschenken, is dan makkelijker. Kortom, die persoon heeft rekening gehouden met het eindpunt van de beweging en de beweging vooruit gepland. Voorbeelden van experimentele taken voor het testen van motorische planning zijn de zwaardtaak (e.g [12]) en de staaftaak [13, 14], waarbij het aantal trials waarin je eindigt in een comfortabele eindhouding ten koste van een comfortabele beginhouding als maat voor het motorisch planvermogen wordt gebruikt (fig. 4 en 5).

In ons systematische review hebben we een overzicht gegeven van het bewijs voor een probleem met de bewegingsplanning bij DCD (4). Eerdere cross-sectionele studies hebben laten zien dat kinderen met DCD problemen ervaren met zowel motorische inbeelding als planning (bijv. [13, 15-18]). Er is echter nog weinig bekend over hoe de vaardigheden motorische inbeelding en planning zich in de loop van de tijd ontwikkelen bij kinderen met DCD.

\section{Ontwikkeling van bewegingsplanning bij kinderen met DCD}

Er is nog weinig longitudinaal onderzoek verricht naar de bewegingsplanning bij kinderen met DCD. Is er
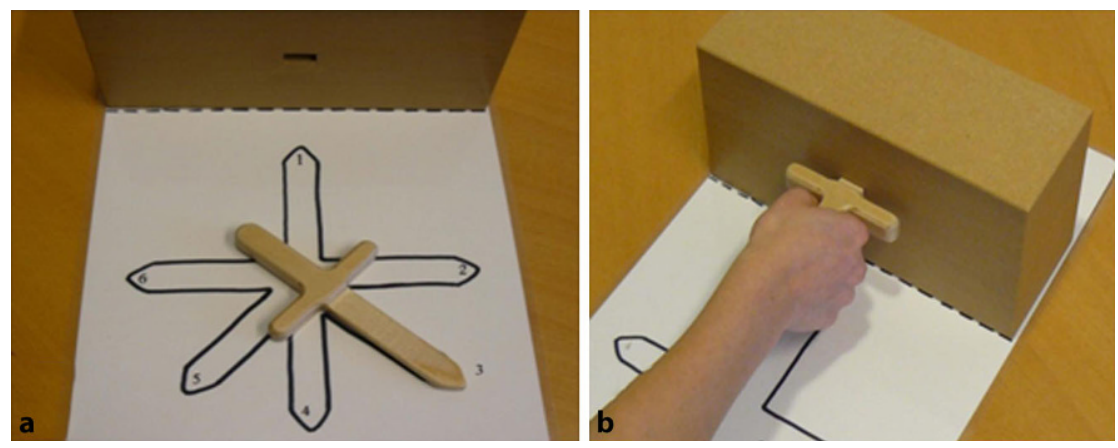

Figuur 4 Opzet van de zwaardtaak. a Zwaard in oriëntatie 3, een oriëntatie waarbij voor rechtshandigen een oncomfortabele beginhouding is vereist om comfortabel te eindigen. b Voorbeeld van een comfortabele eindpositie. 


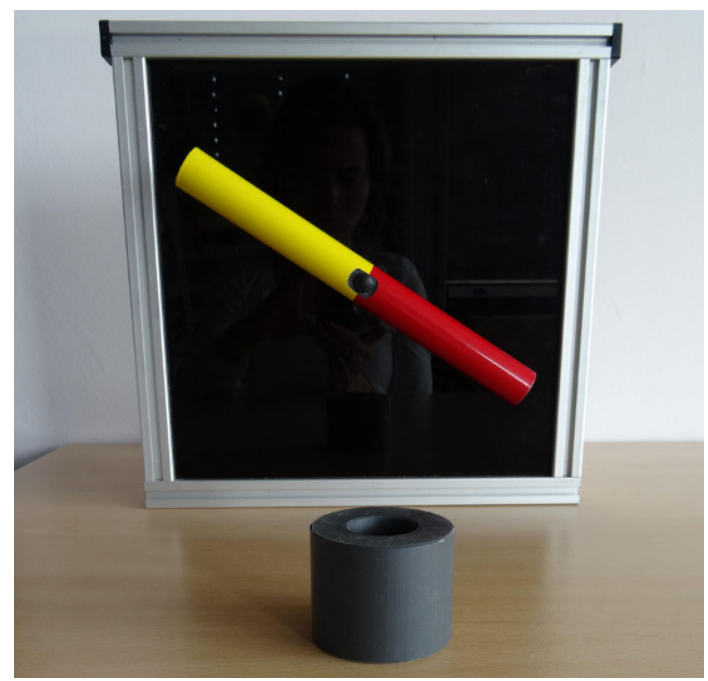

Figuur 5 Opzet van de staaftaak, staaf 120 graden gedraaid.

sprake van verbetering in de loop van de tijd? Om deze vraag te beantwoorden, hebben wij 27 kinderen met DCD (21 jongens, 6 meisjes) in de leeftijd van 6-11 jaar twee jaar lang gevolgd en behalve hun motorische vaardigheden, ook hun motorische inbeeldingsen planningsvaardigheden in kaart gebracht $[19,20]$. Hun prestaties werden vergeleken met die van 27 kinderen die zich standaard ontwikkelen, en die waren gematcht op geslacht en leeftijd ( \pm 4 maanden). Er waren drie meetmomenten waar steeds een jaar tussen zat (T0, T1 en T2).

Resultaten van de handrotatietaak laten zien dat kinderen met DCD langzamer waren en meer fouten maakten dan kinderen zonder motorische problemen tijdens de drie opeenvolgende meetmomenten. De motorische inbeeldingsvaardigheid van kinderen met DCD verbeterde echter wel en deze verbetering over de tijd was vergelijkbaar met die van de kinderen zonder DCD (fig. 6). De doelgerichte wijstaak liet zien dat er bij kinderen met DCD een zekere mate van overeenstemming was tussen uitgevoerde en ingebeelde bewegingstijden en dat deze overeenkomst (uitgedrukt in een correlatie) toenam in de loop van de tijd. Niettemin was die correlatie op alle meetmomenten kleiner in de DCD-groep dan in de controlegroep. Het lijkt er dus op dat kinderen met DCD bij het zich inbeelden van de beweging, taakaspecten - zoals precisie en afstand er wel bij betrekken, maar in mindere mate dan kinderen zonder DCD. Ook bij de motorische planningstaak trad verbetering op bij de kinderen met DCD. Hoewel ze een verminderd motorisch planvermogen hadden bij de start van de studie, was er geen significant verschil meer in prestatie in de twee daarop volgende jaren (fig. 7). Samengevat laten deze resultaten zien dat de eerder gerapporteerde problemen met het vooruitplannen van bewegingen van kinderen met DCD zeker niet allemaal vanzelf verdwijnen tijdens het opgroeien.
Ondanks de waargenomen verbetering lijkt er sprake te zijn van een consistente ontwikkelingsachterstand, maar dan wel taakafhankelijk. In een studie waarbij we twee verschillende motorische planningstaken met elkaar vergeleken [21], kwam inderdaad duidelijk naar voren dat een probleem met motorische planning alleen duidelijk werd bij kinderen met DCD wanneer de zwaardtaak werd gebruikt. De staaftaak vereiste minder precisie aan het eind dan de zwaardtaak.

Hoewel duidelijk is dat kinderen met DCD een probleem hebben met de planning van bewegingen, is het nog onduidelijk waar in het hele proces van bewegen de bewegingsplanning precies stagneert. Problemen met de bewegingsplanning kunnen ontstaan doordat er geen kopie wordt gemaakt van het motorische signaal (de zogeheten efference copy), maar er kunnen ook problemen zijn met het constateren van verschillen tussen de voorspelde en de daadwerkelijke sensorische feedback. Daarnaast kan het zo zijn dat kinderen met DCD moeite hebben met het genereren van een foutsignaal als er een discrepantie wordt geconstateerd tussen de voorspelde en de daadwerkelijke sensorische feedback [22]. Smits-Engelsman en Wilson [23] suggereren dat er bij kinderen met DCD mogelijk meer ruis optreedt in het motorische en sensorische systeem. De processen die mogelijk zijn aangedaan bij kinderen met DCD tijdens de bewegingsplanning zijn weergegeven in fig. 8 (figuur gebaseerd op [22, 24]).

Het is duidelijk dat er problemen zijn in de bewegingsplanning bij kinderen met DCD. $\mathrm{Nu}$ is het van belang om duidelijker te krijgen waar in het proces het fout gaat, zodat gerichtere therapie mogelijk is.

\section{Trainen van motorische vaardigheden bij kinderen met DCD}

De resultaten van de longitudinale studie bieden een interessant aanknopingspunt voor therapie bij kinderen met DCD. Trainingen voor kinderen met DCD ter verbetering van de motorische vaardigheden worden op dit moment met name verzorgd door fysiotherapeuten en ergotherapeuten. Zij passen daarbij vooral taakgerichte benaderingen toe, zoals Cognitive Orientation to daily Occupational Performance (CO-OP) en Neuromotor Task Training (NTT) [25-27]. De CO-OPbenadering richt zich op het uitvoeren van een activiteit die een kind zelf graag wil leren. CO-OP maakt gebruik van cognitieve strategieën, zelfinstructie en aanpassing aan de omgeving, en omvat het Goal-Plan-Do-Checkraamwerk [26].

Bij de NTT-behandeling worden vaardigheden onderzocht door middel van een taakanalyse. Een taak wordt verdeeld in verschillende onderdelen, waardoor gefocust kan worden op de voornaamste problemen binnen een taak. Door gebruik te maken van motorische leerstrategieën, leiden therapeuten de kinderen door de verschillende fasen van een motorische vaar- 


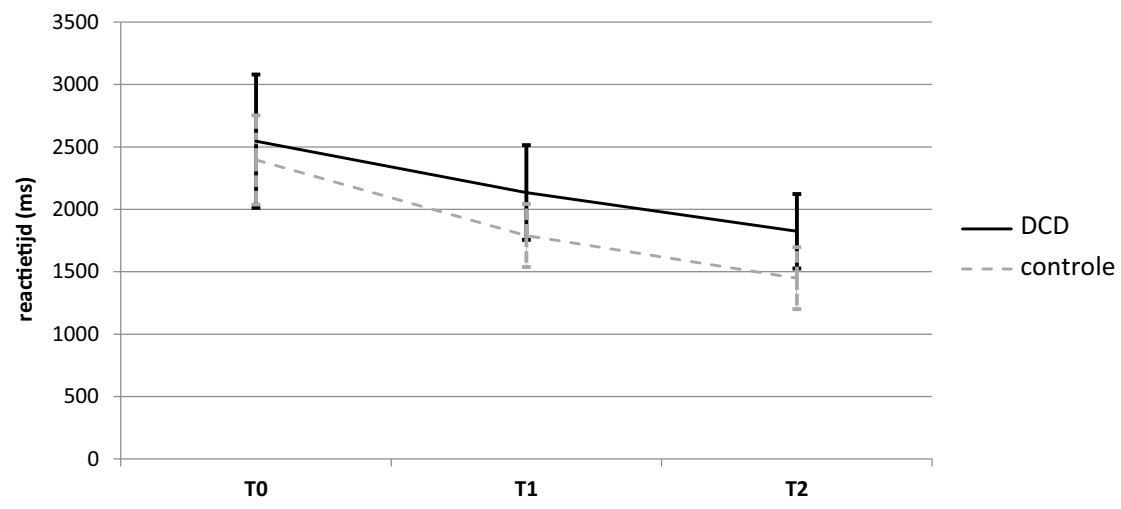

Figuur 6 Reactie tijden bij de handrotatietaak. Uitkomsten van een longitudinale studie met drie meetmomenten (T0, T1, T2). De zwarte lijn geeft de DCD-groep weer, de gestippelde grijze lijn de controlegroep [20]. $\mathrm{DCD}=$ Developmental Coordination Disorder.

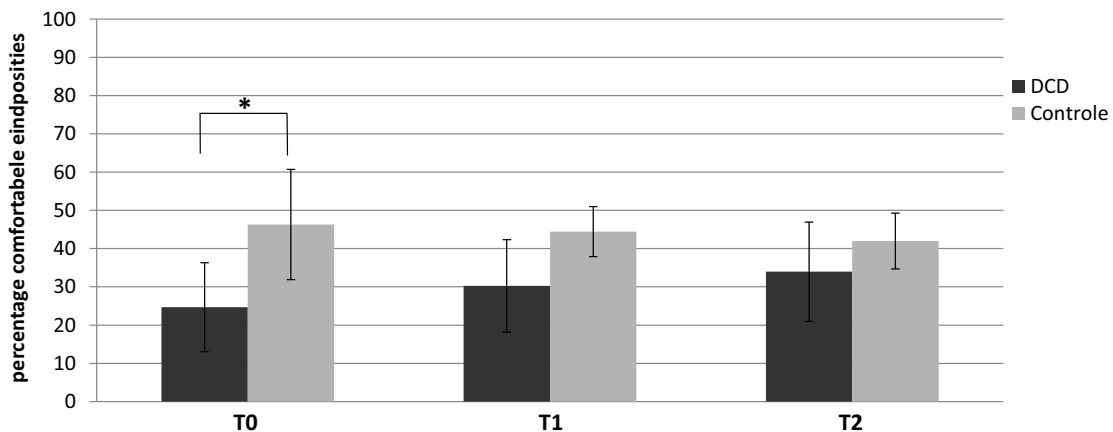

Figuur 7 Uitkomsten op de zwaardtaak. Percentage comfortabele eindposities tijdens de drie meetmomenten (T0, T1, T2). Donkergrijs DCD-groep. Lichtgrijs controlegroep [20]. * $p<0,05$.

digheid heen, waarbij zij stapsgewijs de moeilijkheidsgraad van de taak vergroten [25]. Verschillende studies hebben laten zien dat zowel de CO-OP-behandeling als NTT effectief is voor het verbeteren van de motorische vaardigheden van kinderen met DCD [25, 26, 28-31].

Het aanbieden van deze trainingen vanaf jonge leeftijd kan ervoor zorgen dat niet alleen motorische vaardigheden verbeteren, maar dat ook de aan die vaardigheden gerelateerde problemen verminderen, zoals een gebrek aan fitheid, waardoor sociaal-emotionele problemen kunnen worden voorkomen, denk aan een laag zelfbeeld, angst en sociale isolatie [32, 33].

Om kinderen zich meer bewust te laten worden van hoe ze de gevolgen van een door hen uitgevoerde beweging kunnen voorspellen en hoe ze de vergelijking kunnen maken tussen de uitgevoerde en de ingebeelde beweging, kan motorische inbeelding van toegevoegde waarde zijn. Recent onderzoek bij zowel kinderen [34, 35] als volwassen met motorische problemen [36-40] laat zien dat er twee nieuwe effectieve trainingsmethoden zijn, die zich richten op de bewegingsplanning: (1) motorische inbeeldingstraining en (2) bewegingsobservatie. Beide trainingstechnieken gaan uit van het principe van de gesimuleerde beweging. Daarbij wordt bij motorische inbeeldingstraining een be- weging intern gesimuleerd (vanuit het perspectief van de eerste persoon), terwijl bij bewegingsobservatie de beweging extern gesimuleerd wordt (iemand anders doet de beweging voor). We weten inmiddels dat zowel motorische inbeelding als bewegingsobservatie een belangrijke rol speelt in het leren van complexe motorische taken en dat beide dezelfde neurofysiologische netwerken gebruiken als tijdens bewegingsuitvoering [41]. Recente data laten ook een grote overlap zien in de neuroanatomie tussen deze netwerken en het spiegelneuronensysteem [42-44]. Interessant is dat huidige vormen van motorische training (zoals NTT en COOP) zich voornamelijk richten op de daadwerkelijk uitgevoerde beweging door het lichaam (het onderste gedeelte van fig. 1), terwijl motorische inbeeldingstraining en bewegingsobservatie zich juist richten op het zich voorstellen van een beweging en het voorspellen van de uitkomsten van een beweging (het bovenste gedeelte van fig. 1).

In 2002 zijn de resultaten gepubliceerd van de allereerste studie naar het trainen van inbeelding ter verbetering van de motorische vaardigheden van kinderen met DCD [35]. In deze studie waren kinderen met motorische problemen geïncludeerd, maar helaas waren de inclusiecriteria niet volledig in overeenstem- 


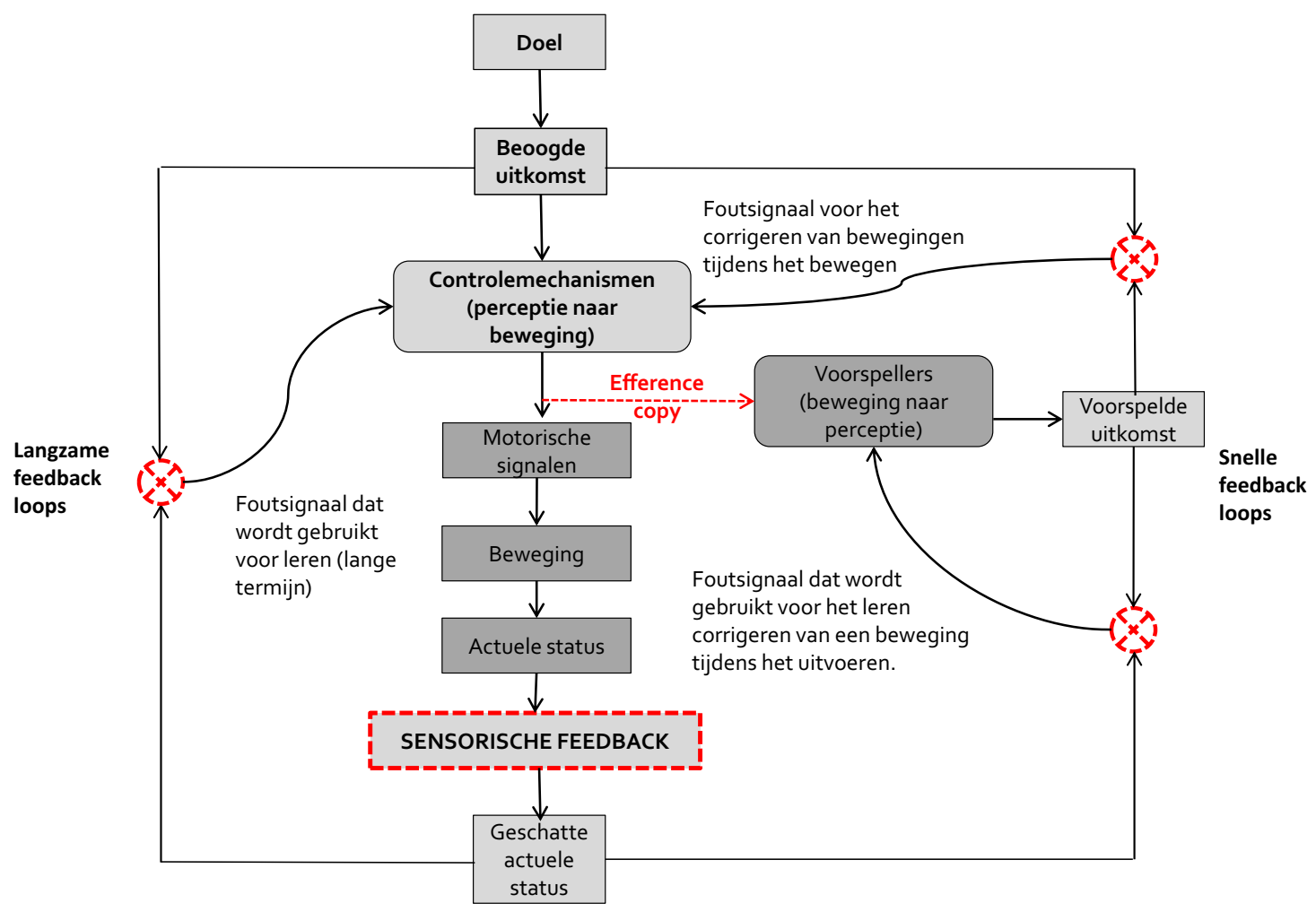

Figuur 8 Schematische representatie van het motorische controlesysteem. Lichtgrijs bewuste motorische representatie. Donkergrijs onbewuste motorische representaties. Met stippellijn processen die mogelijk zijn aangedaan bij kinderen met DCD. Figuur gebaseerd op [22, 24].

ming met de diagnostische criteria voor DCD. De resultaten lieten zien dat motorische inbeeldingstraining tijdens het kijken naar videobeelden van de getrainde beweging, leidde tot hetzelfde resultaat als reguliere motorische training. In 2016 is een replicatiestudie gepubliceerd, maar nu bij een groep kinderen die wel voldeden aan de diagnostische criteria voor DCD [45]. Deze studie kwam tot hetzelfde resultaat. Beide studies zijn uitgevoerd op Australische basisscholen, en in beide studies werd de training gegeven door een onderzoeksassistent.

Wij vroegen ons af of een dergelijke motorische inbeeldingstraining ook zou werken in de fysiotherapiepraktijk in Nederland. Daarom schreven wij een studieprotocol [46] om het effect van motorische inbeeldingstraining te vergelijken met het effect van een reguliere training, de CO-OP-training $[26,27]$. We zijn begonnen met een pilotstudie, waarin vier kinderen de motorische inbeeldingstraining ontvingen en vier kinderen de CO-OP-training. De training bestond uit negen sessies van 45 minuten onder begeleiding van een fysiotherapeut of ergotherapeut, aangevuld met huiswerkoefeningen. De resultaten waren positief: in beide groepen verbeterden de motorische vaardigheden. Motorische vaardigheden werden gemeten met de Movement Assessment Battery for Children versie 2 (mABC-2), waarbij gekeken werd naar zowel de handvaardigheid, balvaardigheid als het evenwicht. De
mABC-2 is een gestandaardiseerde test met normscores voor kinderen van 3-16 jaar. Bij twee kinderen in de motorische inbeeldingsgroep en drie in de CO-OPgroep verbeterden de mABC-2-score met 2 of meer standaardscores [47]. Dit wordt gezien als een klinisch relevante verbetering. De verbetering in motorische vaardigheid werd ook opgemerkt door de kinderen zelf en hun ouders. Motorische inbeeldingstraining lijkt daarmee een succesvolle therapie ter verbetering van de motorische vaardigheden bij kinderen met DCD en kan wellicht ook als aanvulling op reguliere therapie worden gebruikt.

\section{Conclusie en aanbevelingen}

De resultaten uit deze studie ondersteunen de hypothese dat kinderen met DCD moeite hebben met het vooruitplannen van bewegingen. Ondanks verbetering in de loop van de tijd, lijkt er sprake te zijn van een consistente ontwikkelingsachterstand. Longitudinale studies die een langere tijdsperiode omvatten en grotere onderzoekspopulaties zijn nodig om ontwikkeltrajecten per leeftijdsgroep te kunnen bestuderen en om te bepalen of kinderen met DCD uiteindelijk hetzelfde niveau bereiken als kinderen zonder motorische problemen. Daarnaast is het van belang dat we meer inzicht krijgen in de cognitieve factoren die invloed hebben op de effectiviteit van motorische inbeeldingstraining 
bij kinderen met DCD. Het kunnen uitvoeren van motorische inbeelding is gerelateerd aan bijvoorbeeld inhibitie, werkgeheugen en aandacht [48-50]. Dit zijn gebieden waarop kinderen met DCD vaak problemen ervaren en waarvan nog onduidelijk is in hoeverre ze bijdragen aan de prestatieverschillen in experimentele paradigma's en in hoeverre ze invloed kunnen hebben op de effectiviteit van motorische inbeeldingstraining.

Het is ook gebleken dat taakaspecten belangrijk zijn bij het wel of niet vinden van een prestatieverschil tussen kinderen met en zonder DCD. Het belang van aspecten als complexiteit en instructie (bijv. impliciete $v s$. expliciete instructie), moet nader worden onderzocht, om motorische inbeelding als trainingstechniek verder te kunnen ontwikkelen.

Op basis van de uitkomsten van onze studies verwachten wij dat motorische inbeeldingstraining een goede aanvulling kan zijn op reguliere therapie. Kinderen kunnen thuis al video's bekijken van de beweging die zij willen gaan trainen. Daarbij kunnen motorische inbeeldingsopdrachten als huiswerk meegegeven worden. Het is daarvoor echter belangrijk dat de bevindingen van de pilotstudie naar de effectiviteit van deze training in de praktijk worden gerepliceerd en worden bewezen in een grotere klinische trial.

\section{Literatuur}

1. American Psychiatric Association. Diagnostic and statistical manual of mental disorders. 5e druk. Arlington: American Psychiatric Publishing; 2013.

2. Wilson PH, Butson M. Deficits underlying DCD (Chapter 4). In: Geuze RH, redactie. Developmental Coordination Disorder: a review of current approaches. Marseille: Solal Editeurs; 2007. pag. 115-9.

3. Bubic A, Cramon DY von, Schubotz RI. Prediction, cognition and the brain. Front Hum Neurosci. 2010;4:25.

4. Adams IL, Lust JM, Wilson PH, Steenbergen B. Compromised motor control in children with DCD: a deficit in the internal model? A systematic review. Neurosci Biobehav Rev. 2014;47C:225-44.

5. Schuster C, Hilfiker R, Amft O, et al. Best practice for motor imagery: a systematic literature review on motor imagery training elements in five different disciplines. BMC Med. 2011;9:75.

6. Janssen JJ, Sheikh AA. Enhancing athletic performance through imagery: an overview. In: Sheikh AA, Korn ER, redactie. Imagery in sports and physcial performance. Amityville: Baywood Publishing; 1994. pag. 1-22.

7. Sharma N, Pomeroy VM, Baron JC. Motor imagery: a backdoor to the motor system after stroke? Stroke. 2006;37(7):1941-52.

8. Braun SM, Beurskens AJ, Borm PJ, et al. The effects of mental practice in stroke rehabilitation: a systematic review. Arch Phys Med Rehabil. 2006;87(6):842-52.

9. Szameitat AJ, Shen S, Conforto A, Sterr A. Cortical activation during executed, imagined, observed, and passive wrist movements in healthy volunteers and stroke patients. Neuroimage. 2012;62(1):266-80.

10. Horst AC ter, Lier R van, Steenbergen B. Mental rotation task of hands: differential influence number of rotational axes. Exp Brain Res. 2010;203(2):347-54.

11. Ferguson GD, Wilson PH, Smits-Engelsman BC. The influence of task paradigm on motor imagery ability in children with developmental coordination disorder. Hum Mov Sci. 2015;44:81-90.

12. Jongbloed-Pereboom M, Nijhuis-van der Sanden MW, Saraber-Schiphorst N, Craje C, Steenbergen B. Antici- patory action planning increases from 3 to 10 years of age in typically developing children. J Exp Child Psychol. 2013;114(2):295-305.

13. Noten M, Wilson P, Ruddock S, Steenbergen B. Mild impairments of motor imagery skills in children with DCD. Res Dev Disabil. 2014;35(5):1152-9.

14. Jongbloed-Pereboom M, Spruijt S, Nijhuis-van der Sanden MW, Steenbergen B. Measurement of action planning in children, adolescents, and adults: a comparison between 3 tasks. Pediatr Phys Ther. 2016;28(1):33-9.

15. Deconinck FJ, Spitaels L, Fias W, Lenoir M. Is developmental coordination disorder a motor imagery deficit? J Clin Exp Neuropsychol. 2009;31(6):720-30.

16. Lewis M, Vance A, Maruff P, et al. Differences in motor imagery between children with developmental coordination disorder with and without the combined type of ADHD. Dev Med Child Neurol. 2008;50(8):608-12.

17. Williams J, Omizzolo C, Galea MP, Vance A. Motor imagery skills of children with attention deficit hyperactivity disorder and developmental coordination disorder. Hum Mov Sci. 2013;32:121. https://doi.org/10. 1016/j.humov.2012.08.003.

18. Hyde CE, Wilson PH. Impaired online control in children with developmental coordination disorder reflects developmental immaturity. Dev Neuropsychol. 2013;38(2):81-97.

19. Adams ILJ, Lust JM, Steenbergen B (accepted). Development of motor imagery ability in children with Developmental Coordination Disorder - a goal-directed pointing task. Br J of Psychol. Accepted.

20. Adams ILJ, Lust JM, Wilson PH, Steenbergen B. Development of motor imagery and anticipatory action planning in children with developmental coordination disorder - a longitudinal approach. Hum Mov Sci. 2017;55:296-306.

21. Adams IL, Ferguson GD, Lust JM, et al. Action planning and position sense in children with developmental coordination disorder. Hum Mov Sci. 2016;46:196-208. 
22. Gomez A, Sirigu A. Developmental coordination disorder: core sensori-motor deficits, neurobiology and etiology. Neuropsychologia. 2015;79:272-87.

23. Smits-Engelsman BC, Wilson PH. Noise, variability, and motor performance in developmental coordination disorder. Dev Med Child Neurol. 2013;55(Suppl 4):69-72.

24. Blakemore SJ, Wolpert DM, Frith CD. Abnormalities in the awareness of action. Trends Cogn Sci. 2002;6(6):237-42.

25. Niemeijer AS, Smits-Engelsman BC, Schoemaker MM. Neuromotor task training for children with developmental coordination disorder: a controlled trial. Dev Med Child Neurol. 2007;49(6):406-11.

26. Miller LT, Polatajko HJ, Missiuna C, et al. A pilot trial of a cognitive treatment for children with developmental coordination disorder. Hum Mov Sci. 2001;20(1-2):183-210.

27. Smits-Engelsman BCM, Blank R, Kaay AC van der, et al. Efficacy of interventions to improve motor performance in children with developmental coordination disorder: a combined systematic review and meta-analysis. Dev Med Child Neurol. 2013;55(3):229-37.

28. Polatajko HJ, Mandich AD, Miller LT, Macnab JJ. Cognitive orientation to daily occupational performance (CO-OP): part II - the evidence. Phys Occup Ther Pediatr. 2001;20(2-3):83-106.

29. Zwicker JG, Rehal H, Sodhi S, et al. Effectiveness of a summer camp intervention for children with developmental coordination disorder. Phys Occup Ther Pediatr. 2015;35(2):163-77.

30. Jongmans MJ, Linthorst-Bakker E, Westenberg Y, Smits-Engelsman BC. Use of a task-oriented selfinstruction method to support children in primary school with poor handwriting quality and speed. Hum Mov Sci. 2003;22(4-5):549-66.

31. Schoemaker MM, Niemeijer AS, Reynders K, SmitsEngelsman BC. Effectiveness of neuromotor task training for children with developmental coordination disorder: a pilot study. Neural Plast. 2003;10(1-2): 155-63.

32. Kirby A, Sugden DA. Children with developmental coordination disorders. J R Soc Med. 2007;100(4): 182-6.

33. Zwicker JG, Harris SR, Klassen AF. Quality of life domains affected in children with developmental coordination disorder: a systematic review. Child Care Health Dev. 2013;39(4):562-80.

34. Buccino G, Arisi D, Gough P, et al. Improving upper limb motor functions through action observation treatment: a pilot study in children with cerebral palsy. Dev Med Child Neurol. 2012;54(9):822-8.

35. Wilson PH, Thomas PR, Maruff P. Motor imagery training ameliorates motor clumsiness in children. J Child Neurol. 2002;17(7):491-8.

36. Ertelt D, Small S, Solodkin A, et al. Action observation has a positive impact on rehabilitation of motor deficits after stroke. Neuroimage. 2007;36(Suppl 2):T164-T73.

37. Kim JH, Lee BH. Action observation training for functional activities after stroke: a pilot randomized controlled trial. NeuroRehabilitation. 2013;33(4):565-74.
38. Page SJ, Levine P, Leonard A. Mental practice in chronic stroke: results of a randomized, placebo-controlled trial. Stroke. 2007;38(4):1293-7.

39. Pelosin E, Avanzino L, Bove M, et al. Action observation improves freezing of gait in patients with Parkinson's disease. Neurorehabil Neural Repair. 2010;24(8):746-52.

40. Zimmermann-Schlatter A, Schuster C, Puhan MA, et al. Efficacy of motor imagery in post-stroke rehabilitation: a systematic review. J Neuroeng Rehabil. 2008;5:8.

41. Jeannerod M. Neural simulation of action: a unifying mechanism for motor cognition. Neuroimage. 2001;14(1):S103-S9.

42. Motor Cognition JM. What actions tell the self. Oxford: Oxford University Press; 2006.

43. Vogt S, Rienzo FD, Collet C, et al. Multiple roles of motor imagery during action observation. Front Hum Neurosci. 2013;7:807.

44. Gatti R, Tettamanti A, Gough PM, Riboldi E, Marinoni L, Buccino G. Action observation versus motor imagery in learning a complex motor task: a short review of literature and a kinematics study. Neurosci Lett. 2013;540:37-42.

45. Wilson PH, Adams IL, Caeyenberghs K, Thomas P, Smits-Engelsman B, Steenbergen B. Motor imagery training enhances motor skill in children with DCD: a replication study. Res Dev Disabil. 2016;57:54-62.

46. Adams IL, Steenbergen B, Lust JM, Smits-Engelsman BC. Motor imagery training for children with developmental coordination disorder - study protocol for a randomized controlled trial. BMC Neurol. 2016;16(1):5.

47. Adams ILJ, Smits-Engelsman B, Lust JM, Wilson PH, Steenbergen B. Feasibility of motor imagery training for children with developmental coordination disorder - a pilot study. Front Psychol. 2017; https://doi.org/10. 3389/fpsyg.2017.01271.

48. Angelini M, Calbi M, Ferrari A, Sbriscia-Fioretti B, Franca M, Gallese V, et al. Motor inhibition during overt and covert actions: an electrical neuroimaging study. PLOS ONE. 2015;10(5):e126800.

49. Guillot A, Di Rienzo F, Macintyre T, Moran A, Collet C. Imagining is not doing but involves specific motor commands: a review of experimental data related to motor inhibition. Front Hum Neurosci. 2012;6:247.

50. Leonard HC, Bernardi M, Hill EL, Henry LA. Executive functioning, motor difficulties, and developmental coordination disorder. Dev Neuropsychol. 2015;40(4):201-15.

Imke L.J. Adams bewegingswetenschapper en junior onderzoeker op het gebied van Developmental Coordination Disorder

Jessica M. Lust psycholoog en senior onderzoeker op het gebied van Cerebrale Parese en Developmental Coordination Disorder

Bert Steenbergen bewegingswetenschapper en hoogleraar gehandicaptenzorg 